\title{
The effect of recovery satisfaction on citizens loyalty perception: a case study of mobile government services
}

\author{
Ibrahim Almarashdeh \\ Department of Management Information Systems, College of Applied Studies and Community Service, \\ Imam Abdulrahman Bin Faisal University, Saudi Arabia
}

\begin{abstract}
Article Info
Article history:

Received Mar 25, 2018

Revised Feb 15, 2020

Accepted Feb 26, 2020

\section{Keywords:}

Citizens loyalty

Perceived justice

Perceived trust

Procedural justice

Recovery satisfaction

ABSTRACT

Use of mobile services is an integral part of today's life. Organizations, government agencies as well as service providers in the market employ mobile services or application in reaching their citizens or users worldwide. Notably, service failure issues might frustrate users in using mobile service, but usually, service providers would employ the strategy of recovery as solution. Recovery strategy aims to sustain the relationship with users following service failure. Somehow, the factors that might impact recovery process are unclear. It is also unclear if users will use the service again following the completion of recovery process. Hence, in this study, a survey on 743 adults was carried out, and the data were analyzed using SEM to determine the factors that impact users' recovery satisfaction the most and the impact of recovery satisfaction on citizens loyalty to use mobile government in the future. The finding of this study illustrated that expect of self-efficacy, all factors proposed in the research model found to has a significant impact on recovery satisfaction. Among all the supported hypothesis, the highest impact on recovery satisfaction comes from perceived trust in government as the initial predictor to use the service.
\end{abstract}

Copyright (c) 2020 Institute of Advanced Engineering and Science. All rights reserved.

\section{Corresponding Author:}

Ibrahim Almarashdeh,

Department of Management Information Systems,

Imam Abdulrahman Bin Faisal University,

Saudi Arabia.

Email: ibramars@gmail.com

\section{INTRODUCTION}

Mobile technology represents a significant revolution in what a commerce platform should be. As demonstrated by the statistics, M-internet (mobile internet) is now more popular in use as opposed to PC internet. M-internet, as reported in the work of Chen et all, offers larger platform to mobile government as opposed to that offered by e-Government [1]. As reported by International Telecommunication Union (ITU), there were 7 billion mobile users in 2014, amounting to $95 \%$ of the global population, this number is increasing [2]. Both service providers and governments seek for certain services with the capacity to satisfy the demands of users at any time and place. Also, globally, organizations are seeking to improve the citizen's life quality through the integration of information and communications technologies (ICT) with public services including municipal infrastructure and public transport [3]. The use of mobile services assists in the improvement of delivery while lowering the cost and at the same time, the channels for the interaction among people are increased. Somehow, there are challenges including lack of qualified persons especially those that have no access to facilities of IT owing to financial difficulties, the seniors, as well as the issue of trust in certain cultures.

Somehow, for providers of mobile government service, comprehension towards continued post-adoption use of mobile government is the priority as opposed to the initial adoption. This is because, as stated in the work of Choi et al (2011), within the context of mobile service industry, the cost of obtaining 
new users is much greater as opposed to that incurred from maintaining the already available ones [4]. It is thus clear that continued post-adoption usage of user is of great importance. Somehow, little attention has been given to the determinants of postadoption usage particularly within the context of mobile government arena [5]. Hence, by exploring user satisfaction toward mobile government, this study becomes the bridge to the existing gap. This is because in the context of mobile government usage, user satisfaction has been found to be the most essential determinant of continued post-adoption of user $[1,6]$.

Services of mobile government are being enthusiastically developed by governments. Nonetheless, as have been reported by several researches [1,7-11], the existing mobile government literature appears to be more concerned with issues related to first-time adoption as opposed to those relating to continued post-adoption usage, creating yet another gap. Hence, the subject of recovery satisfaction with mobile government services, which is a decisive predictor of post-adoption usage of mobile government services [6] becomes the focus of this study, in order that the gap could be bridged.

It is possible for the government to make available many new services. Somehow, many esearchers $[12,13]$ argued that the government should first know the perspective of the users. Thus, in order to provide better mobile government services, it is important to have the knowledge about how to measure it. Most of previous research in the context of mobile government focused on initial adoption with less concern about post adoption, in the other hand, no study has been found to measure the recovery satisfaction among mobile government users. Hence, the aim of this study is to investigate the factors that effect the user's satisfaction during service recovery and its linkage to user's loyalty to utilize mobile governments, taking into account the factors that play the crucial role in the perspective of citizens. Therefore, this study wishes to answer the following question: which factors has the highest impact on user's satisfaction during service recovery? To which extent recovery satisfaction influence the users loyalty to use mobile government?.

\section{THE IMPORTANT OF MAINTAINING CITIZENS LOYALTY}

The establishment of long-term relationships with the already available citizens is crucial for many reasons. In other words, the present citizens need to be retained because it is a lot more costly to gather new ones [14]. There have been studies that meticulously explored the linkage between citizen's loyalty and its antecedents [15-17]. Accordingly, the antecedents of citizen's loyalty have long been scrutinised by scholars within the context of conventional brick-and-mortar environment. Nonetheless, considerable amount of works has only been concentrating on the manner in which the primary dimensions of e-service quality, impart impact on the loyalty of citizens via the mediation role of citizens-perceived value.

As mentioned by Yang and Peterson (2004), only certain attributes of service quality impart equivalent impacts on citizens-perceived value and loyalty; not all of them [18]. Hence, finding out certain dimensions most instrumental in improving citizens-perceived value and citizen's loyalty amongst numerous hypothetically predictive attributes of service quality and ascertaining the level of their linkage would be highly beneficial. Relevantly, the theory of exit, voice, and loyalty posited by Hirschman (1970) provides the illustration of the types of prospective behavioural responses which may be demonstrated by citizens who are dissatisfied. Accordingly, Colgate and Norris (2001) regard voice and exit as active negative responses, while Boshoff (1997) views loyalty as a passive response [19, 20].

\section{RECOVERY SATISFACTION AND SERVICE FAILURE}

Satisfaction is only partially driving citizens' positive behaviour toward a service provider [21]. Accordingly, the impact imparted by service recovery appears to be more significant on the overall satisfaction as opposed to any other individual facet of the service delivery outcome. Within the general assessment of service experiences, previous research [22] thus mentioned the importance of service recovery component. Hence, the factors determining service recovery satisfaction should thus be understood [23]. As indicated by Etzel and Silverman in 1981, success of recovery efforts would increase the satisfaction level of the dissatisfied citizens, even more than these citizens would have been, in the first place (Etzel and Silverman in 1981).

As mentioned, attracting fresh citizens would incur cost that is considerably greater as opposed to maintaining the current ones. As reported by Reichheld and Sasser in 1990, service organizations could boost their profits up to $85 \%$ through the decrease of the defection rate of the citizens by 5\% [24]. With this under consideration, the establishment of long-term relationships with citizens is crucial to assure success in business. As observed by Gilly (1987), citizens that feel satisfied with the way their complaints are taken care of will feel less dissatisfied, while repurchase probability is increased [25]. Tax et al in 1998 further added that effective handling of complaints can dramatically affect the rate of retention of citizens, draw away the spread of negative word-of-mouth, and increase profitability [26]. 
According to Smith and Bolton in 1998, the response exhibited by the organization towards service failure can potentially re-establish citizens satisfaction or exacerbate citizens' undesirable assessments and motivate them to choose the competitor (Smith and Bolton, 1998). In truth, Hart et al. in 1990, reported that more than $50 \%$ of business response attempts to citizens' complaints in fact reinforce citizens undesirable assessments of a service. Hence, Ok in 2004, stressed the importance of having the knowledge of what creates a successful service recovery and how citizens assess the efforts of recovery by service providers [21].

Possessing the knowledge of the role of service recovery efforts in the establishment of the dimensions of relationship quality will reinforce the acknowledgement towards the need for constant efforts for the provision of citizens satisfaction. In sustaining the enduring relationships and in easing the future relationships with the already available citizens, making these citizens satisfied in an exchange is important. Many studies mentioned efforts of service recovery that are appropriate can transform a service failure into a satisfactory service encounter, contributing to the achievement of secondary satisfaction, and improvement of repurchase intent $[25,27]$ as well as favourable word-of-mouth [21]. Indeed, satisfaction ratings appeared to be higher in organization or employee-initiated recovery as opposed to citizens-initiated recovery. Taking into account the fact that failures are inevitable, acquiring the knowledge on how to appropriately recover from these failures could potentially benefit firms. Such effort of recovery may prove the highest significance in the preservation of citizens loyalty [28].

\section{RESEARCH MODEL AND HYPOTHESES}

Diverse variables have been employed by countless researchers for measuring user acceptance or adoption of mobile government services, as can be referred in Table 1. Somehow, a limitation exists in the measurement of a comprehensive model with the utilisation of service quality trust and risk in addition to perceived cost of services. It should be noted however, that these variables are the primary mobile government acceptance indicators. A new model is hence constructed in order to address the aforesaid limitations, with the inclusion of the variables exhibited in Table 1. The following section will highlight the essential factors included in this paper.

Table 1 highlights the most recent works on service recovery as found in the literature in summarised form. As can be observed, the studies were all pointing to the construct of perceived justice as the key predictor of recovery satisfaction. On the other hand, other equally crucial predictors including perceived, value, trust and risk, service and information quality were neglected. Furthermore, none of the works were specifically covering the context of mobile services or mobile government service. This has motivated this study to explore the impact of the proposed factors on recovery satisfaction. Accordingly, the following section will explain each variable presumed to impart a considerable impact on recovery satisfaction and citizens loyalty utilizing mobile service in general and mobile government in particular.

Table 1. Comparison between proposed variables

\begin{tabular}{lcccccc}
\hline Dimensions & {$[29]$} & {$[30]$} & {$[31]$} & {$[32]$} & {$[33]$} & {$[34]$} \\
\hline Perceived Value & $\mathrm{X}$ & $\mathrm{X}$ & $\mathrm{X}$ & $\mathrm{X}$ & $\mathrm{X}$ & $\mathrm{X}$ \\
Trust in Technology & $\mathrm{X}$ & $\mathrm{X}$ & $\mathrm{X}$ & $\mathrm{X}$ & $\mathrm{X}$ & $\mathrm{X}$ \\
Perceived Risk & $\mathrm{X}$ & $\mathrm{X}$ & $\mathrm{X}$ & $\mathrm{X}$ & $\mathrm{X}$ & $\mathrm{X}$ \\
Trust in government & $\mathrm{X}$ & $\mathrm{X}$ & $\mathrm{X}$ & $\mathrm{X}$ & $\mathrm{X}$ & $\mathrm{X}$ \\
Distributive justice & $\sqrt{ }$ & $\sqrt{ }$ & $\sqrt{ }$ & $\sqrt{ }$ & $\sqrt{ }$ & $\sqrt{ }$ \\
Procedural justice & $\sqrt{ }$ & $\sqrt{ }$ & $\sqrt{ }$ & $\sqrt{ }$ & $\sqrt{ }$ & $\sqrt{ }$ \\
Interactional justice & $\sqrt{ }$ & $\sqrt{ }$ & $\sqrt{ }$ & $\sqrt{ }$ & $\sqrt{ }$ & $\sqrt{ }$ \\
Service Quality & $\sqrt{ }$ & $\sqrt{ }$ & $\mathrm{X}$ & $\mathrm{X}$ & $\mathrm{X}$ & $\mathrm{X}$ \\
Information Quality & $\mathrm{X}$ & $\mathrm{X}$ & $\sqrt{ }$ & $\mathrm{X}$ & $\mathrm{X}$ & $\mathrm{X}$ \\
Perceived Self-efficacy & $\mathrm{X}$ & $\mathrm{X}$ & $\mathrm{X}$ & $\mathrm{X}$ & $\mathrm{X}$ & $\mathrm{X}$ \\
Recovery Satisfaction & $\sqrt{ }$ & $\sqrt{ }$ & $\sqrt{ }$ & $\sqrt{ }$ & $\sqrt{ }$ & $\sqrt{ }$ \\
Citizens loyalty & $\sqrt{ }$ & & $\sqrt{ }$ & $\mathrm{X}$ & $\sqrt{ }$ & $\sqrt{ }$ \\
\hline
\end{tabular}

\subsection{Perceived value}

Perceived value has been identified as a primary precursor of citizens loyalty. For e-commerce, number of researchers [17, 35] mentioned high value as among of the main motivations for citizens patronage. The notion of citizens perceived value has been described by Jiang et al (2016) as the discernment of a consumer towards the net benefits grounded on the discernment of what is obtained and what is provided [35]. Perceived value affects loyalty towards mobile services because it decreases the need of an individual to search different service providers. Low perceived value increases the inclination of citizens to switch to the rivals to obtain more perceived value. This will lead to a decrease in loyalty. In fact, satisfied citizens may still be unlikely to use mobile services if they believe that they are not attaining the greatest 
value for their money. These citizens, according to Chang (2006), will consider other providers to seek better value [36].

The association existing between citizens satisfaction and citizens loyalty seems to be the strongest when the citizens are confident that the e-business vendor they currently use offer them greater overall value as opposed to other vendors. Hence, in this study, a significant moderating effects of citizens perceived value are expected to exist on the linkage between citizens satisfaction and citizens loyalty [37]. Nonetheless, researchers [38], mentioned the presence of uncertainty in terms of the disposition of the relationship between value and satisfaction in addition to the consequences of this relationship to future intents.

For citizens, they assess products and services while taking into account what they have invested, for instance, time, money, and effort, as opposed to what they have attained, for instance, outcomes and sought-after benefits [39]. Perceived value has been regarded as a primary construct in the comprehension of citizens behaviour because this construct leads to satisfaction and behavioural intentions. In this context, intent of repeat purchase and positive word-of-mouth are indicators of citizens loyalty. In the context of services, perceived value is vital in consumption and decision-making [40, 41]. Accordingly, the following is conjectured:

H1: Perceived value has a significant effect on recovery satisfaction.

\subsection{Perceived trust}

It is crucial to have the awareness of how efforts of effective recovery impact the perception of a citizens towards trustworthiness, reliability, and integrity of the provider. The concept of trust has been characterized by Sirdeshmukh, Singh, and Sabol (2002), as a citizen's expectations towards a service provider in terms of dependability and reliability in the delivery of its promises. As stated by [42], it is important that a service provider dependably fulfils the expectation of proficient performance in order that the trust of an exchange partner in a business relationship can be established. Somehow, past studies [21] stated that the quality of relationship and key constructs that researchers have proposed are yet to be comprehensively defined. It seems that recovery satisfaction is closely linked to trust. As empirically evidenced by Tax et al (1998), the handling of complaint and service recovery are closely linked to relationship marketing [26]. Still, nearly all studies of service recovery were only concentrating on the short-term effect and the effectiveness of efforts of recovery and a number of situational factors [21].

\subsubsection{Trust in technology (PTT)}

The literature has demonstrated the use of trust and belief to show how consumers are able to overcome perceived risk in online transactions. Further, as indicated by Anus et al (2011), mobile governments are still in very much new and therefore, for many citizens, they are still clueless when it comes to some issues including security, reliability, as well as technical capacity of the service provider that carries government data [43]. The institutional interpretation of trust is expansively adopted by e-commerce and e-Government research [44]. In the context of mobile government, the traditional viewpoint of trust comes in two types namely trust in government and trust in technology. Trust in government relates to certain entity or department, while trust in technology relates to reliability exhibited by the technology [45, 46]. In the context of electronic and mobile services, trust appears to be a critical success factor. Hence, the following hypothesis is proposed:

Hypothesis 2: Perceived trust in technology has a significant influence on recovery satisfaction.

\subsubsection{Perceived trust of the government (PTG)}

Prior to the endorsement of the initiatives of mobile government, it is important that citizens embrace the confidence that government agencies have the necessitated intelligence and technical resources for the implementation of these systems. Previous researches [47] indicated that a person would first evaluate the exchange partner's trustworthiness before trusting that partner. Relevantly, with services, trust in government is likely to improve public's satisfaction. Likewise, a citizen who feels satisfied with mobile government services may trust and support the government more. Conversely, those who are less satisfied with the services may have their positive attitude toward the government weakened [48, 49].

Websites of federal agency scoring high on online transparency have considerably greater overall satisfaction as opposed to those scoring low. Online transparency impacts citizen's satisfaction while also being associated with desirable future behaviours for instance word of mouth recommendation, repeat website visits, and using the website as the main resource. For public administration, trust of citizen's in their government is a major concern. Additionally, some researchers [50,51] mentioned the concern expressed by public sector leaders about the decline of trust among citizen's since the last several decades. Accordingly, a positive linkage between trust in government and acquiescence in 47 countries has been affirmed by some scholars [47, 52]. 
As posited by the perspective of broad performance, some modern public reforms infer public services of better quality, which translates to great levels of public satisfaction as well as trust in government. The increasing importance of the role of citizen as a consumer has been found to significantly determine the impact that service satisfaction imparts on the levels of trust in government. As noted by some, the role of citizen as citizen's relates to a type of neoliberal movement which stresses on the self-interest of the individual in dealings with government. On the other hand, there are those who view this role as an improvement of democracy which generates more close linkages between citizen's and government [53]. Therefore, following hypothesis is proposed.

Hypothesis 3: Perceived trust in government has a significant effect on recovery satisfaction.

\subsection{Perceived risk $(P R)$}

Among citizen's, mobile governments are yet to be explored fully. In addition, perceiving risk of utilizing the service would prevent users from employing the services [43]. Perceived risk comprises uncertainty associated with behaviour and environment. Behavioural uncertainty occurs and it is caused by the opportunistic behaviour exhibited by online service providers. For instance, online service providers may exploit the impersonal disposition of the electronic environment. Meanwhile, environmental uncertainty is caused by the capricious nature of Internet-based technology that consumer cannot control [45, 54]. Within the context of mobile government, perceived risk causes the intent of user to use the services to decrease. Perceived risk will adversely impact on behavioural intention of consumers to adopt mobile governments. This leads to the construction of the following hypothesis:

Hypothesis 4: Perceived risk has a significant influence on recovery satisfaction.

\subsection{Perceived self-efficacy (SE)}

Self-efficacy as indicated in the work of Tataw and Bazargan-Hejazi (2010), is an important construct for services as it is among the predictors of user satisfaction [55]. This construct describes the belief of user in terms of how he or she is capable to perform certain function [56, 57]. For the scenario of mobile government, self-efficacy is viewed as the level of confidence of the user when accessing and utilizing the government services.

Self-efficacy describes and improves confidence of user, contributing to a positive attitude [57]. In addition, the significant positive influence of self-efficacy has on user satisfaction of information system usage [58]. Hence, the following hypothesis will be tested in this study:

Hypothesis 5: Perceived self-efficacy has a significant influence on recovery satisfaction

\subsection{Service quality (SQ)}

Seeing that mobile technology generates a platform which forms a new service delivery mode that is foreign to businesses, it is necessary to establish a scale of independent service quality for mobile services [59]. It is important that mobile government makes available the rudimentary set of requirements of service quality. Service quality has numerous definitions and these definitions are impacted by the perspective of use. On the other hand, mobile services user perceives service quality as the level of goodness of mobile government services. Service quality is crucial, particularly within the information system (IS) domain. In this regard, several researchers [60-63] indicated that recurrent reduction in frequent disconnection and in response, and lack of reliability and accessibility, will cause many people to be reluctant to employ the system [59].

It is not so simple to measure service quality. This is because each service is different particularly with respect to technology [5]. For instance, websites that offer government services were measured in terms of service quality. At present time, mobile services are measured in terms of service quality because they carry government services. Hence, the following hypothesis is brought forth:

Hypothesis 6: Perceived service quality has significant influence on recovery satisfaction.

\subsection{Information quality}

For users who want to obtain valuable information easily from the system, information quality is of great value. Hence, it is important that information accurateness, reliability, completeness, timeliness, legibility, consistency, relevancy and availability are assured [64]. Also, in all government transactions aspects, information must be presented with a high excellence level. Nonetheless, several limitations have been reported in terms of the amount and type of information which is possibly accessible using mobile government aside from the necessity to promptly make available the pertinent information [65-67].

It has been conjectured that the benefit of mobile government implementation will be massive if the quality of information on this platform is great. Hence, ZamZami, et al (2014) stressed the necessity to scrutinize the condition of information quality using judicious measures [65]. Additionally, researchers [68] 
reported high satisfaction level among clients of technically effective mobile government, applicable system information, and sound citizen's service and maintenance. When people are confident that the information has satisfactory quality, they would assume that the mobile service is competent and valuable. This would consequently promote trust in mobile government $[69,70]$. Hence, the following is conjectured:

Hypothesis 7: Service recovery satisfaction has a positive effect on overall user satisfaction.

\subsection{Perceived justice}

The association between perceived justice and citizen's satisfaction has been highlighted in a number of works. During service failures, low levels of perceived justice can adversely impact the overall user satisfaction [26, 71]. Furthermore, previous studies [21, 33] reported that a corresponding perceptions of justice have positive impact on overall satisfaction. Accordingly, justice theory posits that citizen's perceptions in terms of the fairness of the efforts of service recovery impact citizen's satisfaction as well as future behavioural intentions. Hence, organizations need to have the knowledge of the three justice dimensions (distributive, procedural, and interactional) to enable them to formulate effective strategies of service recovery [27, 72]. The three distinct dimensions of justice have linkage to monetary rewards (distributive), policies embraced by service organization (procedural), and manner and responsiveness exhibited by employee (interactional). All these dimensions could improve the relationship between the service organization and its citizens $[34,73,74]$. Factors linked to the notion of justice are elaborated next.

\subsubsection{Distributive justice}

Distributive justice is linked to the service recovery provided by the company to the consumers [72, 75]. The components of procedure presented to the consumers allows the consumers to assess the process of recovery in terms of flexibility, efficiency, and transparency [76]. Furthermore, perception of justice has positive impact on the purchase intentions of consumers [74].

Service failure/recovery has linkage to the perceived fairness of the outcome of a service failure/recovery [77, 78]. Distributive justice is a notion coined from social exchange theory that stresses the role of equity in forming succeeding exchanges. The principle of equity describes a fair exchange. As posited by this principle, each party in an exchange obtains an outcome which corresponds to his/her contributions to the exchange. Meanwhile, distributive justice revolves around the exchange outcome such as monetary rewards (e.g., discounts, refunds for failed service, coupons) [78, 79]. Hence, based on the discussion, the hypothesis to be tested is as follows:

Hypothesis 8: Distributive justice positively affects recovery satisfaction.

\subsubsection{Procedural justice}

Procedural justice concentrates on the manner in which the outcome is attained. Thus, as indicated by Maxham (1998) satisfaction felt by a citizen's towards the type of recovery strategy offered may still lead to poor recovery evaluation owing to the process that the citizen's had to endure in achieving the recovery outcome [28]. For this situation, procedural justice will be of value because it attempts to resolve conflicts using manners that foster the prolongation of a fruitful relationship between the involved parties, even when outcomes are disappointing to one or all of them [27, 79].

According to Blodgett et al (1997) relate procedural justice to the perceived fairness of procedures and the employed criteria in achieving the recovery outcome [27]. Typically, this justice form includes formal policies and structural considerations that have linkage to service recovery. These, a number of studies $[72,74]$, include responsiveness, waiting time, as well as flexibility during the recovery process. Hence, the following hypothesis is to be tested:

Hypothesis 9: Procedural justice positively affects recovery satisfaction.

\subsubsection{Interactional justice}

Interactional justice is linked to how service failures are managed by service providers in addition to the associated interactions that take place between the citizen's and the service provider [27, 72]. For service, $\mathrm{Ha}$ and Jang (2009) reported that the components of this dimension are: interpersonal sensitivity, dealing with people with dignity and respect, or offering suitable explanations for the service failure [74]. As documented by a number of studies, when people express what they feel to comprise unfair treatment, their responses will mainly revolve around the interpersonal aspects of the situation instead of the recovery outcomes. As have been consistently demonstrated by research findings, the interpersonal treatment is important. Hence, the following statement is hypothesised:

Hypothesis 10: Interactional justice positively affects recovery satisfaction. 


\subsection{Recovery satisfaction and loyalty}

The majority of studies on service recovery were concentrating on the short-term benefits and effectiveness of efforts of service recovery in addition to numerous situational factors. On the other hand, studies that assess the impacts of citizen's assessments of service failure and service recovery satisfaction and behaviour intentions are still insufficient [21, 80, 81].

As indicated by several studies [26, 80], citizen's review and update their satisfaction and behavioural intentions according to the integration of prior assessment and new information. Citizen's who experienced recovery (new information) that is good or excellent would demonstrate improved satisfaction level and higher intent to visit in the future. Relevantly, a number of researchers [21, 71] have stressed the importance of establishing long-term relationships with the present citizen's by way of relationship marketing. Such suggestion has called for the necessity to study service recovery efforts considering that they impact the overall satisfaction of citizens.

Citizen's satisfaction impacts various behaviours with crucial benefits. Hence, it is necessary that organizations constantly make the efforts to increase citizen's satisfaction. In turn, loyalty among citizens can be established. Accordingly, loyalty behaviours can be manifested in an increase in repurchase intentions, repetition sales and in cross sales, while manifesting decrease in price sensitivity and costs. Positive word-ofmouth communications is another demonstration of loyalty behaviour.

Aside from being less price sensitive, satisfied citizens appear to be less affected by competitors, and they also purchase more products or services aside from being demonstrating loyalty for a lengthier period of time $[82,83]$. In fact, the interrelation between satisfaction and loyalty has been documented in past works. According to Oliver (1999), the possibility of developing and transforming satisfaction into loyalty [84]. However, it is possible that loyalty can turn into dissatisfaction if citizens keep feeling unsatisfied. Several past studies have linked satisfaction with service recovery to loyalty. It has been found that recovery satisfaction strongly impacts citizen's loyalty. In this regard, it has been suggested that the fruitful resolution of a citizen's complaint can significantly drive citizen's loyalty. User satisfaction towards service recovery affects loyalty (intention to continue and recommend to others) [85].

Correct solution and handling of a citizen's dissatisfaction has been found to contribute to higher loyalty as opposed to if the citizens had been satisfied. Conversely, dissatisfied citizens with no solution offered to the problem, in addition to feeling dissatisfied with the complaint handling can threaten the service provider in countless ways. For instance, the citizens may stop doing business with the company and choose other companies, and/or may talk about the service provider to others in a negative manner [37, 51]. The following statement is thus hypothesised:

Hypothesis 11: Recovery satisfaction has a positive relationship with citizen's loyalty.

A research model of service recovery is illustrated in Figure 1. The model was constructed according to the literature review. The key constructs of this study have been elaborated by the key findings from the past studies.

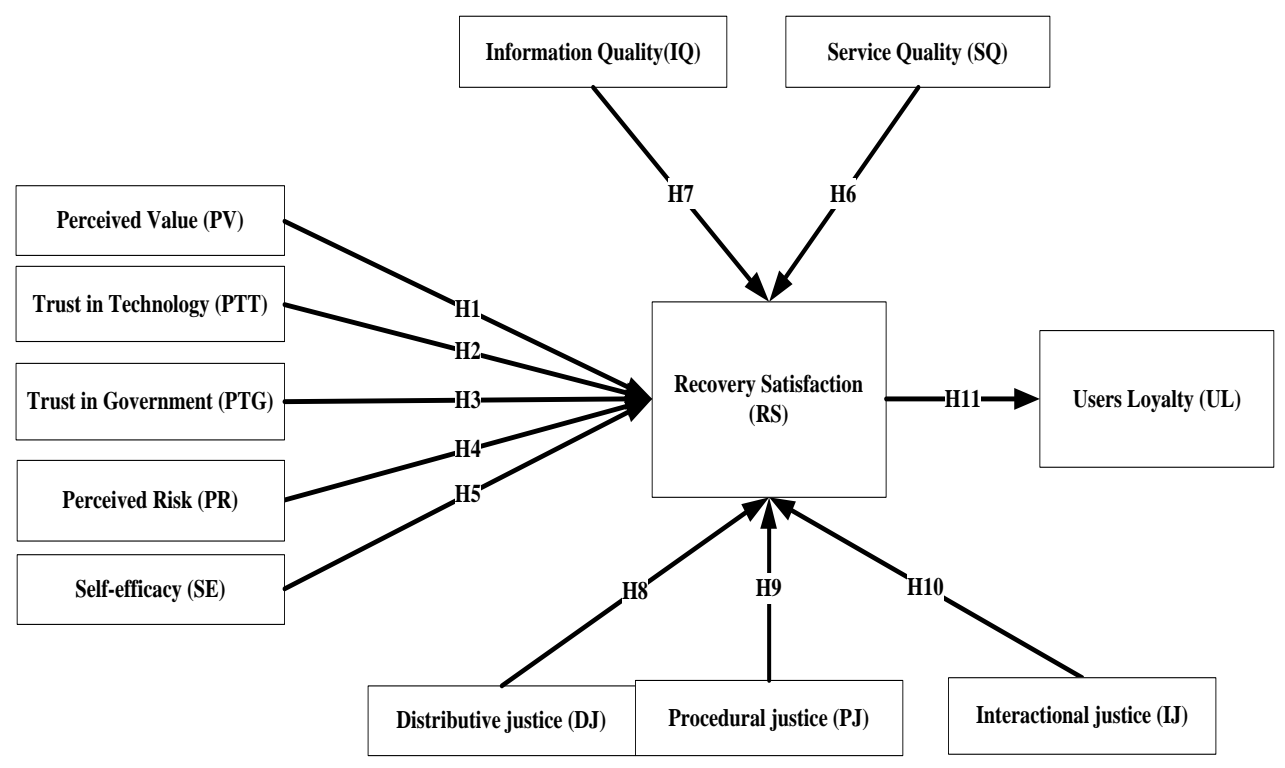

Figure 1. Proposed research model 


\section{METHOD AND DATA COLLECTION}

A total of 743 adult mobile users participated in the study, whereby a survey questionnaire was administered to each of these mobile users in December 2017. The research model proposed in this study contains one exogenous latent variable namely, citizens' loyalty to use mobile government services. Additionally, the model includes one moderator variable that is, recovery satisfaction, in addition to ten (10) endogenous variables which are, Perceived Value, perceived trust on technology, perceived risk, perceived trust in government, distributive justice, interactional justice, procedural justice, self-efficiency, service quality, information quality. For each item in the questionnaire, a 5-point Likert scale is provided for response option. The scale ranges from 1 representing 'Strongly disagree,' to 5 representing 'Strongly agree.'

\subsection{Survey data and constructs validation}

In validating the questionnaire in this study, the first step is the execution of a pilot study. For this study, a total of 25 faculty members were invited to participate. Their responses assisted the researcher in ascertaining the questionnaire items' understandability. In the next validation step, EFA test was performed to ascertain the factor loading of each item, as can be referred in appendix. Meanwhile, the internal reliability of the items was measured using Cronbach's coefficient alpha test. In this regard, a value of Cronbach's Alpha of 0.70 or greater, denotes good reliability [86]. In this study, the variables all passed the reliability test whereby all attained value of 0.70 refer Table 2 demonstrating a good consistency, whereas the scales that this study employed denote $\alpha=0.800$. As can be observed in Table 2 , trust on technology obtained the highest coefficient alpha value $(\alpha=0.884)$ while trust in government achieved the lowest coefficient alpha value $(\alpha=0.707)$.

Table 2. Measurement model's coefficient alpha value

\begin{tabular}{lcll}
\hline Construct & Cronbach alpha & Mean & SD \\
\hline Perceived Value $(P V)$ & .713 & 3.50 & .726 \\
Trust on technology $(P T T)$ & .884 & 3.31 & .620 \\
Trust in Government $(P T G)$ & .707 & 3.34 & .519 \\
Perceived risk $(P R)$ & .719 & 3.06 & .612 \\
Self-efficiency $(S E)$ & .716 & 3.27 & .723 \\
Service quality $(S Q)$ & .711 & 3.38 & .501 \\
Information Quality $(I Q)$ & .832 & 3.30 & .552 \\
Distributive justice $(D J)$ & .821 & 3.43 & .512 \\
Procedural justice $(P J)$ & .724 & 3.33 & .547 \\
Interactional justice $(I J)$ & .710 & 3.35 & .508 \\
Recovery Satisfaction $(R S)$ & .719 & 3.37 & .554 \\
Citizens Loyalty $(C L)$ & .875 & 3.18 & .765 \\
\hline
\end{tabular}

\subsection{Sample information}

Convenience sampling method is used in this study to collect data from 743 adults. The majority of the participants were in the age range of 25-49 years old (87.5\%), Figure 2 can be referred. As for the gender of the participants refer Figure 3, more than half of them $(54.8 \%)$ were males while the rest $(45.2 \%)$ were females. More than half $(54.6 \%)$ of the participants had utilised mobile services between 3 to 7 years, while only a small fraction of them (3.2\%) had utilised mobile services for less than 1 year. Figure 4 can be referred.

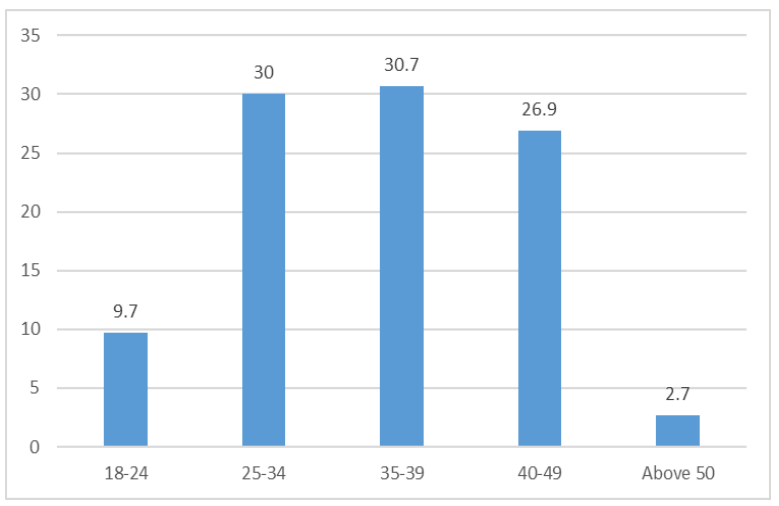

Figure 2. Participant age

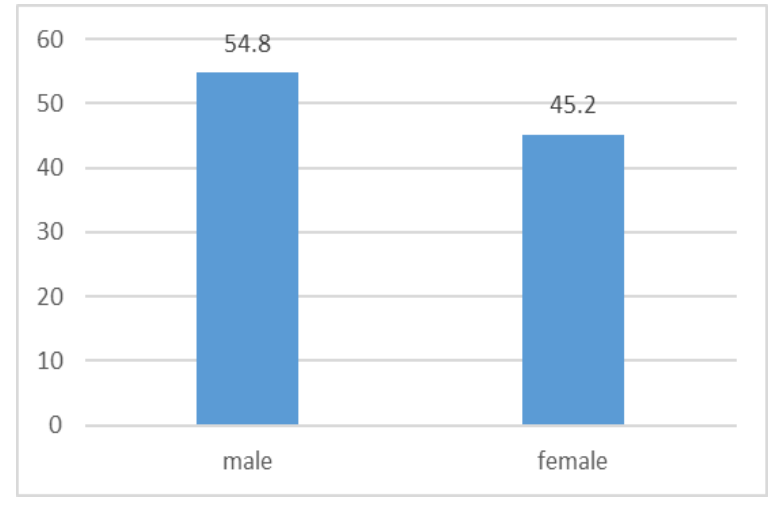

Figure 3. Participant gender 


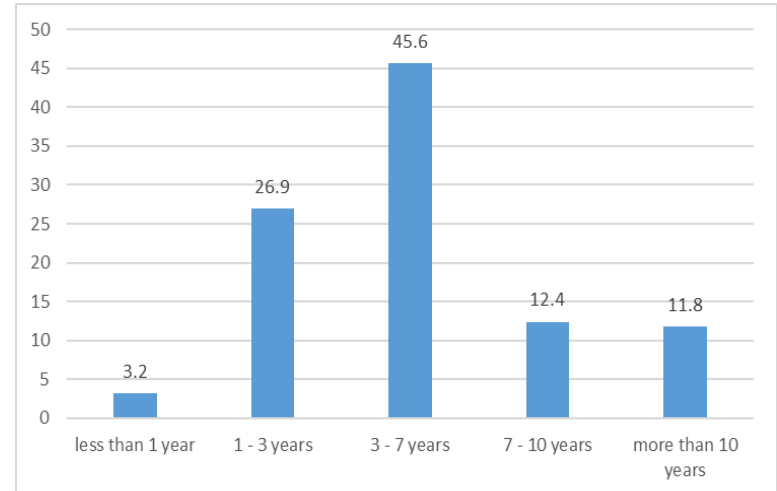

Figure 4. mobile service usage experience

\subsection{Validation of the Structural model}

All relationships in the proposed model were simultaneously tested. For this purpose, structural equation modeling (SEM) Amos 18 was employed. The construction of a measurement model was carried out using Confirmatory Factor Analysis. As evidenced by goodness-of-fit statistics from the meta-analysis, the research model had fairly good fit. This is based on RMR, GFI, CFI, IFI, and root mean square error of approximation (RMSEA) [87, 88]. In particular, CMIN/DF=2.855, $\mathrm{p}<.05$ ( $\leq 3$ recommended); RMR $0.018=0.975(\leq 0.05$ recommended $) ; \mathrm{GFI}=0.975(\leq 0.90$ recommended $) ; \mathrm{CFI}=0.928(\leq 0.90$ recommended $) ;$ $\mathrm{IFI}=0.929(\leq 0.90$ recommended $)$; and $\mathrm{RMSEA}=0.050(\leq 0.08$ recommended $)$.

\section{Testing the research hypothesis}

It is expected that the structural model will test the hypothesized relationships in the model of mobile government services user loyalty proposed in this study. As can be observed in Figure 5, all hypotheses were supported. Further, each demonstrates significant impact on recovery satisfaction except for $\mathrm{H} 5$ which represent the effect of perceived self-efficacy. With respect to H5, no significant effect on recovery satisfaction on using mobile government services has been found. The structural model estimated is illustrated in Figure 5. As proven by the outcomes, for the entire model, the path coefficients are positive and highly significant, with p-value $<0.01$.

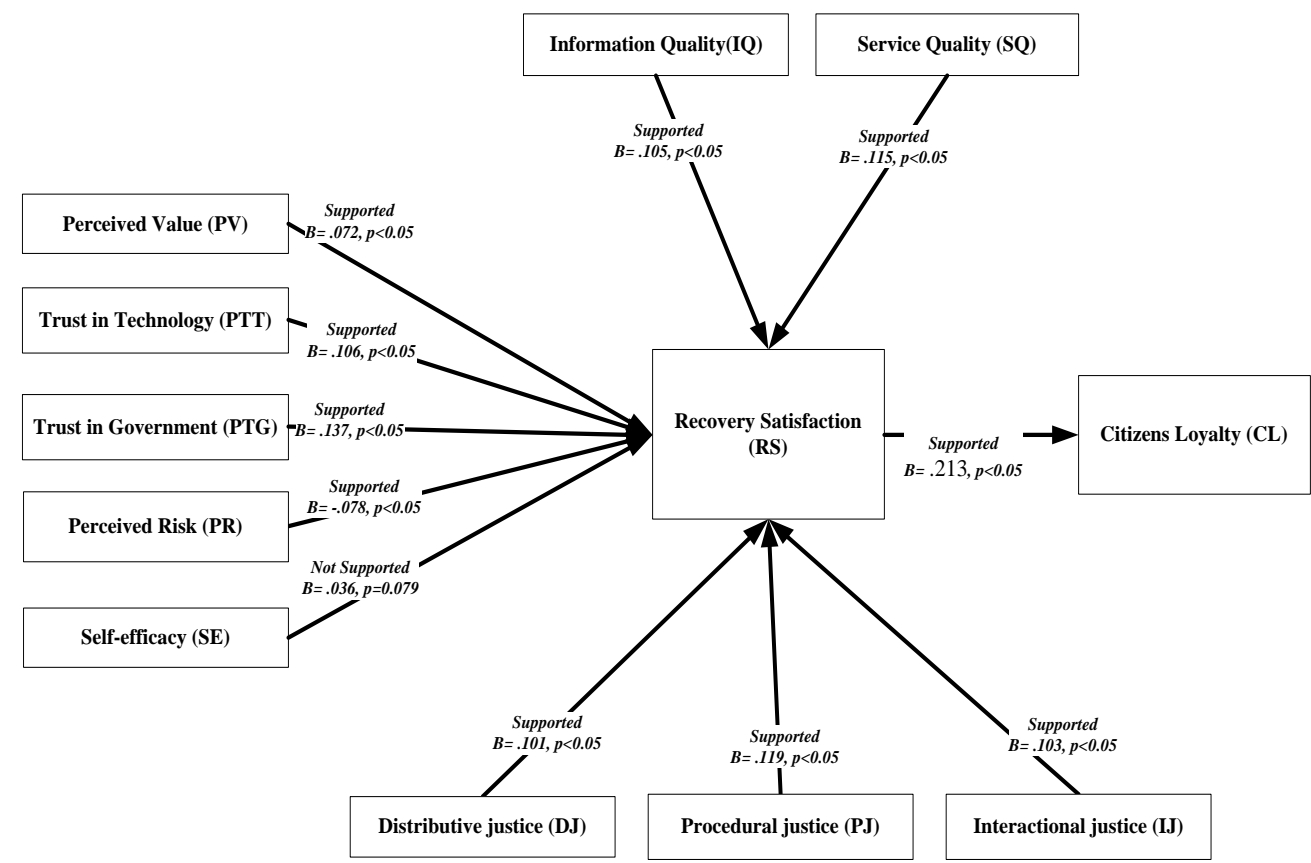

Figure 5. Results of hypotheses testing 
Citizen's loyalty is important to predict the citizens will keep using the mobile government applications. Since recovery satisfaction has a significant mediation effect on citizen's loyalty, this study investigated the indirect effect of all independent variables and their impact on citizen's loyalty to illustrate which factors has a significant indirect effect on citizens loyalty. In order to achieve the above, this study used Amos to perform bootstrap test [89] to indicate if the independent variables has a significant indirect effect on citizens loyalty or not. Table 3 described the indirect effect and significant level tested using bootstrapping. From the table, we can illustrate that all variables have a significant indirect effect on citizen's loyalty. Among all proposed variables, the highest effect comes from perceived trust in governments $(0.029)$ and procedural justice (0.025) and the weakest indirect effect is related to perceived self-efficacy $(0.008)$. The results illustrated that all proposed factors are related to citizen's loyalty and even with the mediation effect of recovery satisfaction these factors still can be used as a predictor of citizen's loyalty. Table 3 can be referred.

Table 3. Results of indirect effect test

\begin{tabular}{ccc}
\hline Variables & Indirect effect & P value \\
\hline IJ & 0.022 & 0.010 \\
DJ & 0.022 & 0.007 \\
PJ & 0.025 & 0.006 \\
PTG & 0.029 & 0.005 \\
PTT & 0.023 & 0.010 \\
VT & 0.015 & 0.007 \\
IQ & 0.022 & 0.009 \\
SQ & 0.024 & 0.009 \\
SE & 0.008 & 0.029 \\
PR & -0.017 & 0.006 \\
\hline
\end{tabular}

\section{DISCUSSION}

The last twenty years have seen the development of mobile services into a highly vital channel as they offer faster processing time and delivery, as well as lower prices. In order to present all-inclusive overview of research on mobile services, this paper employed the data analysis method into this domain. In the future, it is more important to have the comprehension of user loyalty to use mobile government as opposed to the initial adoption for mobile government service. This is because, as recommend by the literature, the cost relating to the acquisition of new user is a lot greater as opposed to the cost of keeping the already available user within the mobile service market [4]. The significance of user continued post-adoption usage research has been acknowledged by many. Nonetheless, within the arena of mobile government, the determinants of postadoption usage have not been sufficiently addressed, and this has created a gap. Hence, study has chosen to explore recovery satisfaction toward mobile government considering that user satisfaction is the most crucial determinant of user continued post-adoption usage in the context of mobile services $[1,6]$.

As mobile government is still new, the focus of government is on recovery satisfaction in order that service usage could be maintained. Through mobile government, government agencies could remain in close proximity to the citizens as the physical distance between citizens and government agencies is bridged, in a sense that communication between both can easily take place using convenient contrivances such as smartphones and tablets. Accordingly, government-citizen relationships can be improved by regularly communicating to the citizens about what the government is doing to serve their best interests. Citizens will continue using the services and, in the future, will use them more.

This study carried out the partial relationship analysis in testing the mediating effects of service recovery on user loyalty. As demonstrated by the results, Perceived Value (PV), Trust on Technology (PTT), Trust in Government (PTG), Perceived risk (PR), Service quality (SQ), Information quality (IQ) Distributive Justice (DJ), Procedural justice (PJ), Interactional justice (IJ) appear to be have a significant impact on Recovery satisfaction (RS) and Citizens loyalty (CL). However, the results do not demonstrate support on the impact of Self-efficiency (SE), on recovery satisfaction.

With respect to the hypothesis tested on recovery satisfaction, stronger links have been found in Trust in Government $(B .137, p<0.001)$, Procedural justice $(B .119, p<0.001)$ and Service quality $(B .115, p<0.001)$. This means that firstly, citizens must have trust on the service provider or government agency and the strategy used with respect to the handling and access to the services. Then, as indicated by several studies $[72,74]$ citizens have to clearly understand the procedure practiced by agency during service failure and recovery. These include responsiveness, waiting time, as well as flexibility during the process of recovery. As mentioned by Huang et al (2015), mobile technology builds a platform which 
forms a new mode of service delivery that is unknown to businesses [59]. Nonetheless, it is still crucial to have service quality improved, because, highest service quality means less anticipation of service failure.

Significant links have also been observed between trust in technology $(B .106, p<0.001)$, information quality $(B .105, p<0.001)$, interactional justice $(B .103, p<0.001)$, distributive justice $(B .101, p<0.001)$ and recovery satisfaction. This means that citizens generally employ the technology he/she trusted first. Then, they will examine how the information obtained via mobile devices is to be recognised, structured, organized, labelled, specific and straight forward [66]. Hence, availability, accuracy, timeliness, completeness, legibility, consistency, relevancy, and reliability of information are crucial in order to ease users in obtaining the sought after information from the system [64].

Information, in all aspects of government transactions, must be presented with a high level of excellence. Somehow, certain limitations exist particularly in terms of the amount and type of information that is potentially accessible via mobile government, beside the necessity to make available the sought after information in real time [65-67, 90]. Interactional justice and distributive justice are crucial issues during service recovery. This owes to the fact that the interactions between the service provider and the citizens or citizens, which relates to interpersonal sensitivity, treating people with dignity and respect, or making available suitable explanations for the service failure, could provide assurance that users will keep utilising the service [74].

After the completion of recovery process, it is crucial that the service provider gives encouragement to the users to re-utilise the service soon. Somehow, first, the recovery process has to show success. It is important that service provider make available to user with proper monetary rewards. These include giving refunds for failed service, discounts, as well as coupons. All these, as indicated by the literature [78, 79], encourage users to utilise the service in future time (distributive justice).

Perceived risk significantly and negatively impacted recovery satisfaction $(B-.078, p=0.001)$. Here, perceived risk appears to impart lower impact as opposed to other factors on recovery satisfaction. Such finding may be attributed to trust in technology and government and service quality $(M=3.31,3.34$, 3.38 respectively) that are consistently high. If the users utilised trusted technology and experienced high service quality, then the feeling of risk in employing the service would be lower for them.

Users perceived value describes the observation regarding the outcomes grounded on the discernment of what is obtained and what is imparted [35]. Perceived value demonstrated significant impact on recovery satisfaction $(B .072, p<0.001)$. In particular, low perceived value increases the inclination of citizens to choose the competitor to increase perceived value, leading to loyalty reduction. The relationship between citizens satisfaction and citizens loyalty seems the strongest in the situation where the citizens are confident that the service provider they currently use offers greater overall value as opposed to the competing providers [37]. Hence, as mentioned by Velázquez et al in 2011, consumers make assessment on products and services taking into account what they have invested (i.e., effort, time, and money) in comparison to what they have attained [39]. In mobile government services domain specifically, users need assurance that the utilisation of the mobile services is more beneficial as opposed to the use of the conventional ones or e-government service.

As demonstrated by the results, perceived self-efficacy did not affect recovery satisfaction $(B .036, p>0.05)$. According to the literature $[56,57]$, self-efficacy explain the belief of user belief regarding how he/she is able to execute certain function. In the context of recovery of mobile government service, perceived self-efficacy of user demonstrates low impact. This is because nearly all service failures will be resolved by the service provider. Hence, users will have less involvement in the process of recovery even though having a good experience in using the service.

Long-term relationship with citizens can be preserved with service recovery. Good or excellent recovery will increase satisfaction and re-visit intentions of citizens [21, 71]. It is therefore crucial for organizations to keep increasing citizen's satisfaction owing to its impact on different behaviors that carry crucial benefits, such as loyalty. Loyalty can be manifested in different ways including increase in repurchase intentions, repetition sales, cross sales, and positive word of mouth. Further, loyalty decreases citizen's sensitivity towards price while contributing to decrease in costs. Citizens who are satisfied with service recovery will be less sensitive towards price, less affected by competitors, purchase greater amount of products or services and are loyal for lengthier time [82, 83].

In this study, satisfaction towards recovery strongly, significantly as well as positively affects user loyalty $(B .213, p<0.001)$. The finding is in agreement with Farquhar and Panther (2007) who documented that the successful resolution of a citizen's complaint can significantly encourage loyalty among users [85]. Furthermore, appropriate solution and handling of citizen's dissatisfaction has been found to contribute to greater level of loyalty as opposed to if the citizens had been satisfied. Contrariwise, a dissatisfied citizen with unresolved issue while also feeling dissatisfied with the way the complaint is handled can adversely 
impact the service provider in countless of ways. For instance, the dissatisfied citizens may abandon the company for the competitor, and may even talk undesirably to others about the service provider [37, 51].

A number of interpretations have been presented by the literature to illustrate the formation of recovery satisfaction. In this paper, the manner in which the efforts of service recovery affect consumer perceptions of satisfaction with a given effort of service recovery has been scrutinised. As mentioned in the work of Oliver and Swan (1989), the literature has been mainly concentrating on perceived justice and service quality in the measurement of recovery satisfaction [91]. Considering that failing service providers would always attempt to restore consumer satisfaction, it is thus crucial for these providers of governments or agency to have sounder comprehension on the manner in which these perceptions are restored. As such, satisfaction of service recovery has been modelled and tested in this study from the viewpoints of mobile services users.

Based on the outcomes, the factors most linked to recovery satisfaction in mobile service are: perceived value, trust on technology, trust in government, perceived risk, service quality, information quality, self-efficiency, distributive justice, procedural justice and interactional justice. All these factors have been hypothesised to affect recovery satisfaction of users, leading to increase their loyalty. The model proposed in this study also provides a foundation for developers, service providers and marketers in their construction of a framework for evaluating mobile services.

This study provides answers to several questions to service providers in their implementation of mobile services. Thus, service providers will be imparted with the capacity in comprehending the manner in which the frustration of citizens could be prevented in utilising the service while also encouraging them to utilise mobile service with no risk perceived. It is important that the procedure, interaction, and treatment are carefully clarified to the citizens during service recovery. These should also be comprehensively comprehended by the service providers' employee particularly those placed at the frontline and call centres.

It is important that the citizens are respected in terms of their time and efforts. Additionally, service provider should understand that during service recovery, having to wait a long time will cause the citizens to be reluctant to utilise the service again. The long wait will also increase the inclination of the citizens to change provider and stop the use of the mobile service and employ the traditional method even though it will be more costly to both the citizens and provider. In addition, making assurance of the service quality through the provision of quality service should take into account the needs of the citizens while satisfying the rudimentary requirement of common mobile devices. Service providers are obliged to offer complete, accurate, legible, consistent, available, applicable, reliable, brief and upfront information to citizens. Information may be circulated by service providers. Somehow, information will be of no value if citizens have no clue of what the information means or if the citizens fail to infer correct conclusions from it.

1: What plan, strategy and procedure are available for service recovery?

- Should a service failure occur, how to sustain the relation with the citizens and how to assure that these citizens will utilise the service again in the future?

- Considering the importance of the value of time, efforts and money to the citizens; how quick is the recovery process and would it be free service during recovery in order to encourage the citizens to use it in the future?

- Given that the service is good; how secure it is to use the service, and how to prevent the risk of using the service?

- Is the information provided by the mobile service clear, short, comprehensible and valuable?

The findings of this study demonstrate the value of recovery satisfaction to illuminate the behaviour of loyalty to the service provider. The findings obtained in this study demonstrate the rich but debatable disposition of perceived trust, value, justice, risk, information quality and service quality add to the exist experience were investigated. The outcomes are in support to the findings of the past works especially in circumstances where value and satisfaction are perceived as main drivers of loyalty among citizens. Theoretically, perceived value is perceived to be a positive impact on loyalty. Still, the question that remains is on whether or not satisfaction mediates this relationship. Accordingly, several scholars believe in a direct value-loyalty relationship [92]. However, this study perceives recovery satisfaction to be just a moderator between these two outcomes. This proves the presence of a strong chain of concatenated impacts between independent variables and loyalty.

A few limitations have been discovered in this study. First of all, this study aimed to gather all the related studies for the meta-analysis. Nonetheless, it is possible that some studies may not have been included. The second limitation of this study is that the studies gathered may have several weaknesses in terms of methodology and measurement errors may also be present as well. Furthermore, the past works have scrutinised a fairly small amount of relationships. Considering that these studies are included in this study's meta-analysis, the connections might be impacted. Lastly, even though the constructs in the proposed model have been regarded to be the primary factors affecting citizens loyalty, other factors could also 
be scrutinised in future works. These factors include perceived enjoyment, experience in service failure, and response time.

In the context of mobile services, it appears that the variables proposed in this study have not been comprehensively studied. For the perusal of future works, streams of literature have brought information regarding this relationship with very diverse outcomes. For example, in cross-sectional studies, and in differing countries, the association that is present between service quality and loyalty is varying and this calls for more investigation. In this study, service quality appears to show the strongest correlation with loyalty behaviour. Still, more investigation is needed.

In the context of IT/IS usage, this study proves that justice should be taken into account in a citizen's recovery satisfaction model. From the findings obtained in this study, several suggestions for future research are brought into attention. Providers of mobile service should also execute measures in order that recovery satisfaction in every service encounter could be improved. For the improvement of recovery satisfaction and to increase loyalty of user, the corresponding measures could be taken by practitioners based on the dimensions of trust (in government and technology), value (time, money, effort value) as well as justice (distributive, procedural, interactional justice).

Finally, this the first study that investigated the recovery satisfaction in mobile government context. Based on deep search in the literature in the field of mobile government and mobile services in general, we did not find any related studies to recovery satisfaction in mobile government context. This study fills the gap in mobile government user satisfaction while its focal point is on user satisfaction toward mobile government considering that user satisfaction needs to be maintained based on every new service, on a fixed basis. As a new and rapidly growing field, the concepts and theories of mobile government are still in a premature stage.

\section{CONCLUSIONS}

The perception of users during service recovery has been explored in this study, for the purpose of assisting the service provider in improving the service. Accordingly, data were gathered from the participants and analyses were executed using SEM. The outcomes obtained demonstrate support to all hypotheses except for the construct of self-efficacy which did not show a significant impact on recovery satisfaction. Furthermore, the highest influence on recovery satisfaction appeared to be from perceived trust in government, procedural justice as well as service quality. The weakest significant impact of recovery satisfaction is exhibited by perceived risk and perceived value. The study is valuable to the body of knowledge regarding mobile services, e-government and public administration by the employment of current survey data for the exploration of the role of service recovery in establishing the loyalty of a user in utilising government services. This study highlights on what users want from service providers if service failure happens in addition to what should be done by service provider in order to sustain a sound relationship with users who utilise the service. The outcomes demonstrate that during service recovery, preserving a sound relationship with users, calls for a clear picture of justice (e.g., treatment, procedure). Additionally, information that is brief and clear, with the resolution of common mobile devices will inspire users to utilise the service together with the required service grounded on their needs in addition to the effort, time and money for services use. This study deduced that increased interactions with government using mobile services are valuable and effective in enhancing the perception of citizens towards government and they will use mobile government services in future. For future works, response time during service recovery which might be a good predictor of recovery satisfaction should be comprehensively examined.

\section{APPENDIX}

\begin{tabular}{|c|c|c|}
\hline Items & Code & Loading \\
\hline \multicolumn{3}{|l|}{ INFORMATION QUALITY ITEMS (IQ) } \\
\hline The mobile government services provide information that is exactly what you need. & IQI & 0.850 \\
\hline The mobile government services provide information you need at the right time. & IQ2 & 0.830 \\
\hline The mobile government services provide sufficient information. & IQ4 & 0.848 \\
\hline The mobile government services provide information that is easy to understand. & IQ5 & 0.794 \\
\hline The mobile government services provide up-to-date information. & IQ6 & 0.850 \\
\hline When I have a problem, the mobile government services "help desk" will show a sincere interest in solving it & $S Q 2$ & 0.727 \\
\hline The mobile government services can secure my transactions record and activities & $\widehat{S Q 3}$ & 0.753 \\
\hline The "help desk" of mobile government services will never be too busy to respond to my requests & $S Q 4$ & 0.734 \\
\hline The "help desk" of mobile government will give prompt service & $\widehat{S Q 5}$ & 0.782 \\
\hline
\end{tabular}




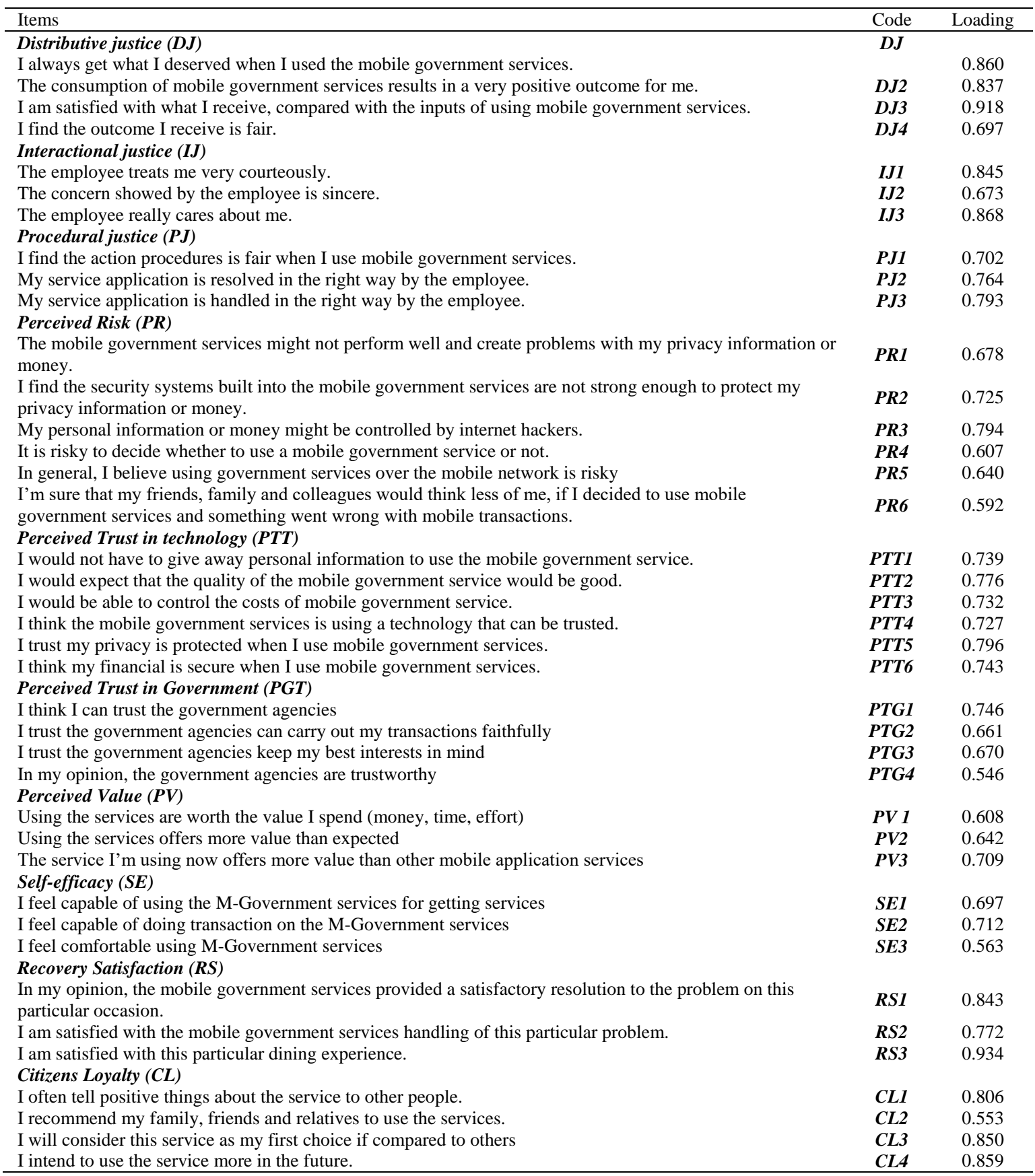

\section{ACKNOWLEDGEMENTS}

I would like to express my sincere thanks to all the participants in this study whom provides a critical comment about using the mobile government. Also, I would like to thank the Imam Abdulrahman Bin Faisal University for funding this project under the application number: 2019-386-ASCS.

\section{REFERENCES}

[1] Z.-J. Chen, D. Vogel, and Z.-H. Wang, "How to satisfy citizens? Using mobile government to reengineer fair government processes," Decision Support Systems, vol. 82, pp. 47-57, 2016.

[2] Statista, "The Statistics Portal Statistics and facts on mobile Internet usage," 2017. [Online]. Available: http://www.statista.com/topics/779/mobile-internet/

[3] M. Almiani, A. Razaque, and A. Al Dmour, "Privacy preserving framework to support mobile government services," International Journal of Information Technology and Web Engineering (IJITWE), vol. 11, no. 3, pp. 65-78, 2016. 
[4] H. Choi, Y. Kim, and J. Kim, "Driving factors of post adoption behavior in mobile data services," Journal of Business Research, vol. 64, no. 11, pp. 1212-1217, 2011.

[5] I. Almarashdeh and M. K. Alsmadi, "How to make them use it? Citizens acceptance of M-government," Applied Computing and Informatics, vol. 13, no. 2, pp. 194-199, 2017.

[6] A. Bhattacherjee, "Understanding information systems continuance: an expectation-confirmation model," MIS quarterly, vol. 25, no. 3, pp. 351-370, 2001.

[7] A. Alawneh, H. Al-Refai, and K. Batiha, "Measuring user satisfaction from e-Government services: Lessons from Jordan," Government Information Quarterly, vol. 30, no. 3, pp. 277-288, 2013.

[8] C.-L. Hsu, H.-P. Lu, and H.-H. Hsu, "Adoption of the mobile Internet: An empirical study of multimedia message service (MMS)," Omega, vol. 35, no. 6, pp. 715-726, 2007.

[9] S.-Y. Hung, C.-M. Chang, and S.-R. Kuo, "User acceptance of mobile e-government services: An empirical study," Government Information Quarterly, vol. 30, no. 1, pp. 33-44, 2013.

[10] Y. Liu, H. Li, V. Kostakos, J. Goncalves, S. Hosio, and F. Hu, "An empirical investigation of mobile government adoption in rural China: A case study in Zhejiang province," Government Information Quarterly, vol. 31, no. 3, pp. 432-442, 2014.

[11] R. Rannu, S. Saksing, and T. Mahlakõiv, "Mobile Government: 2010 and Beyond," APCICT B. Koteles, Ed., ed: Mobi Solutions Ltd, 2010.

[12] A. Parasuraman, V. A. Zeithaml, and A. Malhotra, "ES-QUAL: A multiple-item scale for assessing electronic service quality," Journal of service research, vol. 7, no. 3, pp. 213-233, 2005.

[13] I. Almarashdeh, A. Althunibat, and N. F. Elias, "Developing a Mobile Portal Prototype for E-government Services," Journal of Applied Sciences, vol. 14, no. 8, pp. 791-797, 2014.

[14] P. Kotler, J.T. Bowen, J.C. Makens, and S. Baloglu, "Marketing for hospitality and tourism," Pearson, 2017.

[15] V. A. Ibáñez, P. Hartmann, and P. Z. Calvo, "Antecedents of customer loyalty in residential energy markets: Service quality, satisfaction, trust and switching costs," The Service Industries Journal, vol. 26, no. 6, pp. 633-650, 2006.

[16] C. Y. Wang, "Service quality, perceived value, corporate image, and customer loyalty in the context of varying levels of switching costs," Psychology \& Marketing, vol. 27, no. 3, pp. 252-262, 2010.

[17] F. Zeng, Z. Hu, R. Chen, and Z. Yang, "Determinants of online service satisfaction and their impacts on behavioural intentions," Total Quality Management, vol. 20, no. 9, pp. 953-969, 2009.

[18] Z. Yang and R. T. Peterson, "Customer perceived value, satisfaction, and loyalty: The role of switching costs," Psychology \& Marketing, vol. 21, no. 10, pp. 799-822, 2004.

[19] M. Colgate and M. Norris, "Developing a comprehensive picture of service failure," International Journal of service industry management, vol. 12, no. 3, pp. 215-233, 2001.

[20] C. Boshoff, "An experimental study of service recovery options," International Journal of service industry management, vol. 8, no. 2, pp. 110-130, 1997.

[21] C. Ok, "The effectiveness of service recovery and its role in building long-term relationships with customers in a restaurant setting," Kansas State University, 2004.

[22] M. S. Bhandari, Y. Tsarenko, and M. J. Polonsky, "A proposed multi-dimensional approach to evaluating service recovery," Journal of Services Marketing, vol. 21, no. 3, pp. 174-185, 2007.

[23] A. B. del Río-Lanza, R. Vázquez-Casielles, and A. M. Díaz-Martín, "Satisfaction with service recovery: Perceived justice and emotional responses," Journal of Business Research, vol. 62, no. 8, pp. 775-781, 2009.

[24] F. F. Reichheld and J. W. Sasser, "Zero defections: Quality comes to services," Harvard business review, vol. 68, no. 5, pp. 105-111, 1990.

[25] M. C. Gilly, "Postcomplaint processes: from organizational response to repurchase behavior," Journal of Consumer Affairs, vol. 21, no. 2, pp. 293-213, 1987.

[26] S. S. Tax, S. W. Brown, and M. Chandrashekaran, "Customer evaluations of service complaint experiences: implications for relationship marketing," The journal of marketing, vol. 63, no. 2, pp. 60-76, 1998.

[27] J. G. Blodgett, D. J. Hill, and S. S. Tax, "The effects of distributive, procedural, and interactional justice on postcomplaint behavior," Journal of retailing, vol. 73, no. 2, pp. 185-210, 1997.

[28] J. G. Maxham III, "Service Recovery's Influence on Complainant Attitudes and Intentions: A Perceived Justice Framework," LSU Historical Disertations and Theses, 1998.

[29] V. T. Quy and P. T. B. Lan, "The Impact of Bank Responses to Recovery Service Satisfaction," Asian Economic and Financial Review, vol. 5, no. 9, pp. 1076, 2015.

[30] S. Jha and M. Balaji, "Perceived justice and recovery satisfaction: the moderating role of customer-perceived quality," Management \& Marketing, vol. 10, no. 2, pp. 132-147, 2015.

[31] D. Nikbin, M. Marimuthu, S. S. Hyun, and I. Ismail, "Relationships of perceived justice to service recovery, service failure attributions, recovery satisfaction, and loyalty in the context of airline travelers," Asia Pacific Journal of Tourism Research, vol. 20, no. 3, pp. 239-262, 2015.

[32] O. O. Tektas, "Perceived justice and post-recovery satisfaction in banking service failures: Do commitment types matter?," Service Business, vol. 11, no. 4, pp. 851-870, 2017.

[33] Y.-W. Chang and Y.-H. Chang, "Does service recovery affect satisfaction and customer loyalty? An empirical study of airline services," Journal of Air Transport Management, vol. 16, no. 6, pp. 340-342, 2010.

[34] N. Y. Jung and Y.-K. Seock, "Effect of service recovery on customers' perceived justice, satisfaction, and word-of-mouth intentions on online shopping websites," Journal of Retailing and Consumer Services, vol. 37, pp. 23-30, 2017. 
[35] L. Jiang, M. Jun, and Z. Yang, "Customer-perceived value and loyalty: how do key service quality dimensions matter in the context of B2C e-commerce?," Service Business, vol. 10, no. 2, pp. 301-317, 2016.

[36] H. H. Chang, "An empirical evaluation of performance measurement systems for total quality management," Total Quality Management, vol. 17, no. 8, pp. 1093-1109, 2006.

[37] H. H. Chang, Y.-H. Wang, and W.-Y. Yang, "The impact of e-service quality, customer satisfaction and loyalty on e-marketing: Moderating effect of perceived value," Total Quality Management, vol. 20, no. 4, pp. 423-443, 2009.

[38] C.-F. Chen and M.-H. Tsai, "Perceived value, satisfaction, and loyalty of TV travel product shopping: Involvement as a moderator," Tourism management, vol. 29, no. 6, pp. 1166-1171, 2008.

[39] B. M. Velázquez, I. G. Saura, and M. E. R. Molina, "Conceptualizing and measuring loyalty: Towards a conceptual model of tourist loyalty antecedents," Journal of vacation marketing, vol. 17, no. 1, pp. 65-81, 2011.

[40] Y.-T. H. Chiu, W.-I. Lee, and T.-H. Chen, "Environmentally responsible behavior in ecotourism: Antecedents and implications," Tourism management, vol. 40, pp. 321-329, 2014.

[41] M. Oviedo-García, M. Castellanos-Verdugo, M. Vega-Vázquez, and F. Orgaz-Agüera, "The Mediating Roles of the Overall Perceived Value of the Ecotourism Site and Attitudes Towards Ecotourism in Sustainability Through the Key Relationship Ecotourism Knowledge-Ecotourist Satisfaction," International Journal of Tourism Research, vol. 19, no. 2, pp. 203-213, 2017.

[42] D. Sirdeshmukh, J. Singh, and B. Sabol, "Consumer trust, value, and loyalty in relational exchanges," Journal of Marketing, vol. 66, no. 1, pp. 15-37, 2002.

[43] S. Anus, F.A. Qureshi, S. Malik, A. Abbasi, A. Chaudhry, and S.N. Mirza, "Trust and initial acceptance of Mobile Banking in Pakistan," International Journal of Scientific \& Engineering Research, vol. 2, no. 8, p. 14, 2011.

[44] T. El-Kiki and E. Lawrence, "Mobile user satisfaction and usage analysis model of mgovernment services," in Second European Mobile Government Conference (Euro mGov 2006), pp. 1-12, Brighton, UK, 2006.

[45] F. Bélanger and L. Carter, "Trust and risk in e-government adoption," The Journal of Strategic Information Systems, vol. 17, no. 2, pp. 165-176, 2008.

[46] I. Almarashdeh, "An Overview Of Technology Evolution: Investigating The Factors Influencing Non-Bitcoins Users To Adopt Bitcoins As Online Payment Transaction Method," Journal of Theoretical and Applied Information Technology, vol. 96, no. 13, pp. 3984-3993, 2018.

[47] P. Jimenez and G. S. Iyer, "Tax compliance in a social setting: The influence of social norms, trust in government, and perceived fairness on taxpayer compliance," Advances in accounting, vol. 34, pp. 17-26, 2016.

[48] J. E. Cohen, "Citizen satisfaction with contacting government on the internet," Information Polity, vol. 11, no. 1, pp. 51-65, 2006.

[49] M. S. Akram and A. Malik, "Evaluating citizens' readiness to embrace e-government services," in Proceedings of the 13th Annual International Conference on digital government research, pp. 58-67, 2012.

[50] R. B. Denhardt, J. V. Denhardt, and T. A. Blanc, "Public administration: An action orientation," Cengage Learning, 2013.

[51] D. Nikbin, I. Ismail, and M. Marimuthu, "The relationship between informational justice, recovery satisfaction, and loyalty: the moderating role of failure attributions," Service Business, vol. 7, no. 3, pp. 419-435, 2013.

[52] G. Richardson, "The relationship between culture and tax evasion across countries: Additional evidence and extensions," Journal of International Accounting, Auditing and Taxation, vol. 17, no. 2, pp. 67-78, 2008.

[53] T. Christensen and P. Lægreid, "Trust in government: The relative importance of service satisfaction, political factors, and demography," Public Performance \& Management Review, vol. 28, no. 4, pp. 487-511, 2005.

[54] I. Almarashdeh, "The important of service quality and the trust in technology on users perspectives to continues use of mobile services," Journal of Theoretical \& Applied Information Technology, vol. 96, no. 10, 2018.

[55] D. B. Tataw and S. Bazargan-Hejazi, "Impact of the health services utilization and improvement model (HUIM) on self efficacy and satisfaction among a Head Start population," Journal of health and human services administration, vol. 33, no. 2, pp. 228-256, 2010.

[56] C.-S. Yu, "Factors Affecting Individuals to Adopt Mobile Banking: Empirical Evidence from the UTAUT Model," Journal of Electronic Commerce Research, vol. 13, no. 2, pp. 104-121, 2012.

[57] A. Bandura, "Social foundations of thought and action," Englewood Cliffs, NJ: Prentice-Hall., 1986.

[58] S. Gountas, J. Gountas, and F. T. Mavondo, "Exploring the associations between standards for service delivery (organisational culture), co-worker support, self-efficacy, job satisfaction and customer orientation in the real estate industry," Australian Journal of Management, vol. 39, no. 1, pp. 107-126, 2014.

[59] E. Y. Huang, S.-W. Lin, and Y.-C. Fan, "MS-QUAL: mobile service quality measurement," Electronic Commerce Research and Applications, vol. 14, no. 2, pp. 126-142, 2015.

[60] P. Seddon, "A respecification and extension of the DeLone and McLean model of IS success," Information systems research, vol. 8, no. 3, pp. 240-253, 1997.

[61] W. DeLone and E. McLean, "Information systems success: the quest for the dependent variable," Information systems research, vol. 3, no. 1, pp. 60-95, 1992.

[62] I. A. Almarashdeh, N. Sahari, N. a. M. Zin, and M. Alsmad, "The Success of Learning Management System Among Distance Learners in Malaysian Universitie," Journal of Theoretical and Applied Information Technology, vol. 21 no. 2, pp. 80-91, 2010.

[63] W. Delone and E. McLean, "The DeLone and McLean model of information systems success: A ten-year update," Journal of management information systems, vol. 19, no. 4, pp. 9-30, 2003.

[64] I. Almarashdeh, "Sharing instructors experience of learning management system: A technology perspective of user satisfaction in distance learning course," Computers in Human Behavior, vol. 63, pp. 249-255, 2016. 
[65] I. ZamZami, M. Mahmud, and A. Abubakar, "Information quality evaluation of mobile-Government (mGovernment) Services," in International Conference on Human-Computer Interaction, pp. 280-285, 2014.

[66] S. Hoober, E. Berkman, "Designing Mobile Interfaces: Patterns for Interaction Design," O'Reilly Media, Inc., 2011.

[67] J. Carroll, "'What's in It for Me?': Taking M-Government to the People," BLED Proceedings, pp. 49, 2006.

[68] S. M. Lee, H.-H. Lee, J. Kim, and S.-G. Lee, "ASP system utilization: customer satisfaction and user performance," Industrial Management \& Data Systems, vol. 107, no. 2, pp. 145-165, 2007.

[69] D. H. McKnight, V. Choudhury, and C. Kacmar, "Developing and validating trust measures for e-commerce: An integrative typology," Information systems research, vol. 13, no. 3, pp. 334-359, 2002.

[70] J. Kim, S. Hong, J. Min, and H. Lee, "Antecedents of application service continuance: A synthesis of satisfaction and trust," Expert Systems with Applications, vol. 38, no. 8, pp. 9530-9542, 2011.

[71] J. G. Maxham III and R. G. Netemeyer, "A longitudinal study of complaining customers' evaluations of multiple service failures and recovery efforts," Journal of Marketing, vol. 66, no. 4, pp. 57-71, 2002

[72] J. R. McColl-Kennedy and B. A. Sparks, "Application of fairness theory to service failures and service recovery," Journal of service research, vol. 5, no. 3, pp. 251-266, 2003.

[73] M. J. Bitner, B. H. Booms, and M. S. Tetreault, "The service encounter: diagnosing favorable and unfavorable incidents," The journal of marketing, vol. 54, no. 1, pp. 71-84, 1990.

[74] J. Ha and S. S. Jang, "Perceived justice in service recovery and behavioral intentions: The role of relationship quality," International Journal of Hospitality Management, vol. 28, no. 3, pp. 319-327, 2009.

[75] Y.-F. Kuo and C.-M. Wu, "Satisfaction and post-purchase intentions with service recovery of online shopping websites: Perspectives on perceived justice and emotions," International Journal of Information Management, vol. 32, no. 2, pp. 127-138, 2012.

[76] J. Wirtz and A. S. Mattila, "Consumer responses to compensation, speed of recovery and apology after a service failure," International Journal of service industry management, vol. 15, no. 2, pp. 150-166, 2004.

[77] B. Bugg Holloway, S. Wang, and S. E. Beatty, "Betrayal? Relationship quality implications in service recovery," Journal of Services Marketing, vol. 23, no. 6, pp. 385-396, 2009.

[78] A. K. Smith, R. N. Bolton, and J. Wagner, "A model of customer satisfaction with service encounters involving failure and recovery," Journal of marketing research, vol. 36, no. 3, pp. 356-372, 1999.

[79] D. Nikbin, et. al., "Perceived justice in service recovery and switching intention: Evidence from Malaysian mobile telecommunication industry," Management Research Review, vol. 35, no. 3/4, pp. 309-325, 2012.

[80] A. K. Smith and R. N. Bolton, "An experimental investigation of customer reactions to service failure and recovery encounters: paradox or peril?," Journal of service research, vol. 1, no. 1, pp. 65-81, 1998.

[81] K. De Ruyter and M. Wetzels, "Customer equity considerations in service recovery: a cross-industry perspective," International Journal of service industry management, vol. 11, no. 1, pp. 91-108, 2000.

[82] M. Zineldin, "Total relationship management (TRM) and total quality management (TQM)," Managerial Auditing Journal, vol. 15 , no. 1/2, pp. 20-28, 2000.

[83] M. Zineldin, "Total relationship and logistics management," International journal of physical distribution \& logistics management, vol. 34, no. 3/4, pp. 286-301, 2004.

[84] R. L. Oliver, "Whence Consumer Loyalty," Journal of Marketing, vol. 63, pp. 33-44, 1999.

[85] J. D. Farquhar and T. Panther, "The more, the merrier? An exploratory study into managing channels in UK financial services," International Review of Retail, Distribution and Consumer Research, vol. 17, no. 1, pp. 43-62, 2007.

[86] J. F. Pallant, "SPSS survival manual: a step by step guide to data analysis using SPSS," (version 12) (Book, Whole)," Crows Nest, N.S.W: Allen \& Unwin, 2004.

[87] A. Davey and J. Savla, "Statistical power analysis with missing data: A structural equation modeling approach," Routledge, 1 edition, 2009.

[88] R. P. Bagozzi and Y. Yi, "On the evaluation of structural equation models," Academic of Marketing Science, vol. 16, pp. 74-94, 1988.

[89] G. W. Cheung and R. S. Lau, "Testing mediation and suppression effects of latent variables: Bootstrapping with structural equation models," Organizational research methods, vol. 11, no. 2, pp. 296-325, 2008.

[90] I. Almarashdeh and M. Alsmadi, "Heuristic evaluation of mobile government portal services: An experts' review," in 11th International Conference for Internet Technology and Secured Transactions (ICITST), Barcelona, pp. 427-431, 2016.

[91] R. L. Oliver and J. E. Swan, "Consumer perceptions of interpersonal equity and satisfaction in transactions: a field survey approach," The journal of marketing, vol. 31, no. 2, pp. 21-35, 1989.

[92] H. C. Oh, "An empirical study of the relationship between restaurant image and customer loyalty," Virginia Tech, 1995. 